\title{
The literate mind
}

\author{
Zohar Eviatar · Falk Huettig
}

Published online: 6 July 2021

(C) The Author(s) 2021

Homo sapiens ' ability to invent and culturally transmit technologies has had an enormous impact on planet earth. Human technologies, ranging from starting a fire, stone tools, farming and the wheel, to genetic engineering and deep learning networks, have reshaped all aspects of our lives. One such technology, writing, invented about six thousand years ago in Mesopotamia, has played a particularly key role. It is difficult to overstate its importance for the course of human history. The characterstics of written language are thought to have created a need for more precise definitions of terms and more logical analyses of concepts (Havelock \& Havelock, 1963), facilitating critical debate and encouraging more abstract thinking (Goody \& Watt, 1963) in societies that adopted

\section{Z. Eviatar}

Psychology Department, University of Haifa, Mount Carmel, Haifa, Israel

\section{Z. Eviatar}

Institute for Information Processing and Decision Making, University of Haifa, Mount Carmel, Haifa, Israel

F. Huettig ( ()

Max Planck Institute for Psycholinguistics, Nijmegen,

The Netherlands

e-mail: Falk.Huettig@mpi.nl

F. Huettig

Centre for Language Studies, Radboud University,

Nijmegen, The Netherlands writing over the past six millennia. Research over the last forty years has revealed that literacy, i.e., the ability to read and write, changed humanity enormously not only a societal level, but also transforms individual minds and brains. Literacy enhances phonological awareness (Lukatela et al., 1995; Morais et al., 1979, 1986; Prakash et al., 1993), prediction during spoken language processing (Favier et al., 2021; Huettig \& Pickering, 2019; Mishra et al., 2012), the perception of facial emotions (Eviatar, 1997), face recognition (Van Paridon et al., 2021), mirror image discrimination (Fernandes et al., 2021; Kolinsky et al., 2011; Pegado et al., 2014), visual search (Olivers et al., 2014), verbal memory (Demoulin \& Kolinsky, 2016; Smalle et al., 2019), and Raven's non-verbal intelligence (Hervais-Adelman et al., 2019; Olivers et al., 2014; Skeide et al., 2017). Research on the effect of literacy thus is a powerful tool to investigate how the human mind works.

The present special issue of the Journal of Cultural Cognitive Science is the result of the productive discussions about literacy and writing systems that took place at two meetings of the Society for the Cognitive Science of Culture (SCSC). The researchers of the society believe that it is indispensable for modern cognitive science to look at different cultures and diverse participant populations in order to understand the mind and brain. Given the mostly Western background of cognitive science, it is necessary to establish what kind of findings from the mostly 
Western research body generalize to diverse populations and across cultures. The society investigates in particular how cultural inventions such as written words, numbers, music, and belief systems, shape the mind and brain from the beginning of our lives and through exposure to cultural objects across the life span. The Society for the Cognitive Science of Culture (SCSC) aims to facilitate the discussion of the latest developments in the cognitive science of culture to provide a platform for exchanging ideas and a network to foster collaborations among interested researchers. The society especially encourages participation by researchers from all parts of the world.

The 3rd SCSC meeting was organized by Zohar Eviatar and Tali Bitan from the University of Haifa from 18 to 20 February 2019 on Mount Carmel in Haifa, Israel. The 4th SCSC meeting was held at BITS Pilani University in Goa, India, from 3 to 7 February 2020 and hosted by Veeky Baths (BITS Pilani University Goa), Ramesh Mishra (University of Hyderabad), and Falk Huettig (Max Planck Institute for Psycholinguistics and Radboud University Nijmegen). The articles in this special issue are an outcome of these two meetings and address a broad range of issues related to literacy and writing systems.

Franchetto, (2021) argues in her paper that there is a need to break with a narrow conception of 'writing' and that there are other 'writings' that need careful examination. She points out that in most South American Amerindian languages, the original words for writing refer to mythic-shamanic graphisms that transform bodies and objects into social beings. The Kuikuro of Southern Amazonia, for instance, use the root ahehi to refer to the tracing of maps and schemes on the floor, which has come to mean 'writing' since the very first exposure to this new object and practice. Franchetto makes the case that all Amazonian cases are transpositions that deviate from Western conceptions of literacy.

Maia, (2021) reviews four decades of fieldwork with the Javaé and the Karaja peoples of Central Brazil and describes experimental field work as an exercise in what he calls bricolage. Maia reflects not only on methodological challenges that experimental researchers face in the field but also on deeper anthropological and epistemological issues that need to be taken into consideration if cognitive science is to be properly practiced in non-WEIRD (Western Educated Industrial Rich Democratic) societies.
Daniels, (2021) points out that reading and writing rarely have been studied within a single discipline or by the same individuals or groups of scholars. He gives an interesting account of the history of the study of writing systems and describes his syllable-based typology and a number of concepts from linguistics, for readers beyond the field of linguistics.

Khatteb Abu-Liel et al., (2021) discuss that the most common form of computer-mediated communication (CMC) script-switching has been the Latinization of non-Latin scripted languages. They present the case of Arabizi, where Arabic speaking youth rely on the use of the Latin script as the main writing system when communicating through the electronic medium in Spoken Arabic (SA). They studied the attitudes of Arab adolescents in northern Israel towards the use of Arabizi (Latinized Arabic) in CMC and towards Modern Standard Arabic (MSA). Their findings suggest that although students all use Arabizi (and report that it is easier and more accessible to them) they consider MSA important and valuable as it is related to their identity as Arabs.

Arunkumar et al., (2021) conducted a conceptual replication of Alexander Luria's (1976) famous study that found that people who never learnt to read and write do not perceive visual illusions. In two carefully controlled experiments with 161 participants with varying literacy levels ranging from complete illiterates to high literates in Chennai (India), Arunkumar and colleagues observed that literacy does not meaningfully affect the identification of visual illusions. Their findings also raise some questions about other reports of cultural effects on visual illusion perception.

Vágvölgyi et al., (2021) present a systematic literature review exploring the similarities and differences identified in empirical studies investigating both functional illiterates and people with developmental dyslexia. They find that there is lack of studies directly comparing functional illiterates with people with developmental dyslexia and a huge variance between studies in how they approached the concept of functional illiteracy, particularly concerning the applied definition, terminology, criteria for inclusion in the sample, research focus, and outcome measures. Vágvölgyi and colleagues discuss the need for more direct comparisons in order to understand to what extent functional illiteracy and dyslexia share common characteristics. 
Morais and Kolinsky present two twin opinion papers about the effects of literacy on society. Morais and Kolinsky, (2021a) discusses the concept of critical literacy in relation to language, thought, and reasoning. They discuss how literacy gives birth to critical literacy and explain why, at the end of this process, critical literacy becomes hard to distinguish from thinking and reasoning. Morais and Kolinsky, (2021b) discusses the wider relationship between literacy and thinking about the future and argues that forecasting is literacy-based.

Hu et al., (2021) investigated the effect of literacy experience on syntactic priming in Mandarin in sixty Chinese older adults from Hebei province. They observed that literates produced robustly more prepositional object constructions than illiterates compatible with usage-based theories of language processing that propose that all linguistic skills are a function of accumulated experience with language across life. $\mathrm{Hu}$ and colleagues also present evidence suggesting that cumulative syntactic priming in literates may be related mostly to comprehending others, whereas in illiterates it is also associated with repeating selfproductions.

Pathak et al., (2021) present a study with seventy public school teenage students from Kathmandu (Nepal) who participated in a number of language comprehension, language production and cognitive control tasks. They observed that participants receiving education in L2 as medium of instruction performed better than those receiving education in $\mathrm{L} 1$ as the medium of instruction, in all the measures of language comprehension and cognitive control. Pathak et al. interpret their findings as showing that receiving education in L2 enhances linguistic and cognitive performance in L1.

Finally, Inoue et al., (2021) examined the relations between reading self-concept, reading interest, taskfocused behavior, and reading skills, and whether culture moderates the relations among these factors in a longitudinal study with Grade 2 children across Canadian and Japanese cultural contexts. Task-focused behavior was uniquely associated with reading skills in both samples but the association between reading self-concept and reading skills was stronger in the Canadian than in the Japanese sample. Inoue and colleagues conclude that although there is a positive association between motivation and reading skills, the developmental dynamics between them may not be the same across the two cultures.

Funding Open Access funding enabled and organized by Projekt DEAL.

Open Access This article is licensed under a Creative Commons Attribution 4.0 International License, which permits use, sharing, adaptation, distribution and reproduction in any medium or format, as long as you give appropriate credit to the original author(s) and the source, provide a link to the Creative Commons licence, and indicate if changes were made. The images or other third party material in this article are included in the article's Creative Commons licence, unless indicated otherwise in a credit line to the material. If material is not included in the article's Creative Commons licence and your intended use is not permitted by statutory regulation or exceeds the permitted use, you will need to obtain permission directly from the copyright holder. To view a copy of this licence, visit http://creativecommons.org/licenses/by/4.0/.

\section{References}

Arunkumar, M., van Paridon, J., Ostarek, M., \& Huettig, F. (2021). Do illiterates have illusions? A conceptual (non)replication of Luria (1976). Journal of Cultural Cognitive Science. https://doi.org/10.1007/s41809-02100080-x

Daniels, P. T. (2021). Foundations of graphonomy. Journal of Cultural Cognitive Science. https://doi.org/10.1007/ s41809-020-00067-0

Demoulin, C., \& Kolinsky, R. (2016). Does learning to read shape verbal working memory? Psychonomic Bulletin \& Review, 23(3), 703-722.

Eviatar, Z. (1997). Language experience and right hemisphere tasks: The effects of scanning habits and multilingualism. Brain and Language, 58(1), 157-173.

Favier, S., Meyer, A. S., \& Huettig, F. (2021). Literacy can enhance syntactic prediction in spoken language processing. Journal of Experimental Psychology: General, Advance online publication. https://doi.org/10.1037/ xge0001042.

Fernandes, T., Arunkumar, M., \& Huettig, F. (2021). The role of the written script in shaping mirror-image discrimination: Evidence from illiterate, Tamil literate, and Tamil-Latinalphabet bi-literate adults. Cognition, 206, 104493.

Franchetto, B. (2021). Amerindian conceptions on 'writing' as object and practice. Journal of Cultural Cognitive Science. https://doi.org/10.1007/s41809-020-00069-y

Goody, J., \& Watt, I. (1963). The consequences of literacy. Comparative Studies in Society and History, 5(3), 304-345.

Havelock, E. A., \& Havelock, L. (1963). Preface to Plato (Vol. 1). Harvard University Press,

Hervais-Adelman, A., Kumar, U., Mishra, R. K., Tripathi, V. N., Guleria, A., Singh, J. P., \& Huettig, F. (2019). Learning to 
read recycles visual cortical networks without destruction. Science Advances, 5(9), 262.

Hu, Y., Lv, Q., Pascual, E., Liang, J., \& Huettig, F. (2021). Syntactic priming in illiterate and literate older Chinese adults. Journal of Cultural Cognitive Science.

Huettig, F., \& Pickering, M. J. (2019). Literacy advantages beyond reading: Prediction of spoken language. Trends in Cognitive Sciences, 23(6), 464-475.

Inoue, T., Georgiou, G. K., Maekawa, H., et al. (2021). Cultural influences on the relationship between self-concept, interest, task-focused behavior, and reading skills. Journal of Cultural Cognitive Science. https://doi.org/10.1007/ s41809-020-00071-4

Khatteb Abu-Liel, A., Eviatar, Z., \& Nir, B. (2021). Arabic teenagers' attitudes to electronic writing in Arabizi. Journal of Cultural Cognitive Science. https://doi.org/10.1007/ s41809-020-00057-2

Kolinsky, R., Verhaeghe, A., Fernandes, T., Mengarda, E. J., Grimm-Cabral, L., \& Morais, J. (2011). Enantiomorphy through the looking glass: Literacy effects on mirror-image discrimination. Journal of Experimental Psychology: General, 140(2), 210-238.

Lukatela, K., Carello, C., Shankweiler, D., \& Liberman, I. (1995). Phonological awareness in illiterates: Observations from Serbo-Croatian. Applied Psycholinguistics, 16(4), 463-487.

Maia, M. (2021). Non-WEIRD experimental field work as bricolage: A discourse on methods in the investigation of deixis and coreference in the Karajá language of Central Brazil. Journal of Cultural Cognitive Science.

Mishra, R. K., Singh, N., Pandey, A., \& Huettig, F. (2012). Spoken language-mediated anticipatory eye movements are modulated by reading ability: Evidence from Indian low and high literates. Journal of Eye Movement Research, 5(1), 1-10. https://doi.org/10.16910/jemr.5.1.3

Morais, J., \& Kolinsky, R. (2021a). Seeing thought: A cultural cognitive tool. Journal of Cultural Cognitive Science. https://doi.org/10.1007/s41809-020-00059-0

Morais, J., Kolinsky, R. (2021b). Seeing thought in the future: Literate forecasting and forecasting literacy. Journal of Cultural Cognitive Science.

Morais, J., Cary, L., Alegria, J., \& Bertelson, P. (1979). Does awareness of speech as a sequence of phones arise spontaneously? Cognition, 7(4), 323-331.
Morais, J., Bertelson, P., Cary, L., \& Alegria, J. (1986). Literacy training and speech segmentation. Cognition, 24(1-2), 45-64.

Olivers, C. N. L., Huettig, F., Singh, J. P., \& Mishra, R. K. (2014). The influence of literacy on visual search. Visual Cognition, 22(1), 74-101.

Pathak, L., Rijal, S., \& Pathak, P. (2021). Instruction in second language enhances linguistic and cognitive abilities in first language as well: Evidence from public school education in Nepal. Journal of Cultural Cognitive Science.

Pegado, F., Nakamura, K., Braga, L. W., Ventura, P., Nunes Filho, G., Pallier, C., \& Dehaene, S. (2014). Literacy breaks mirror invariance for visual stimuli: A behavioral study with adult illiterates. Journal of Experimental Psychology: General, 143(2), 887-894.

Prakash, P., Rekha, D., Nigam, R., \& Karanth, P. (1993). Phonological awareness, orthography and literacy. In R. Scholes (Ed.), Literacy and language analysis (pp. 55-70). Lawrence Erlbaum.

Skeide, M. A., Kumar, U., Mishra, R. K., Tripathi, V. N., Guleria, A., Singh, J. P., \& Huettig, F. (2017). Learning to read alters cortico-subcortical cross-talk in the visual system of illiterates. Science Advances, 3(5), e1602612.

Smalle, E. H. M., Szmalec, A., Bogaerts, L., Page, M. P. A., Narang, V., Misra, D., Araújo, S., Lohagun, N., Khan, O., Singh, A., Mishra, R. K., \& Huettig, F. (2019). Literacy improves short-term serial recall of spoken verbal but not visuospatial items-Evidence from illiterate and literate adults. Cognition, 185, 144-150.

Vágvölgyi, R., Bergström, K., Bulajić, A. et al. Functional illiteracy and developmental dyslexia: looking for common roots. A systematic review. J Cult Cogn Sci (2021). https:// doi.org/10.1007/s41809-021-00074-9

Van Paridon, J., Ostarek, M., Arunkumar, M., \& Huettig, F. (2021). Does neuronal recycling result in destructive competition? The influence of learning to read on the recognition of faces. Psychological Science., 32, 459-465.

Publisher's Note Springer Nature remains neutral with regard to jurisdictional claims in published maps and institutional affiliations. 